PR-25

\title{
SYNTHESIS OF INDONESIAN KAOLIN-nZVI (IK-nZVI), EVALUATION FOR THE REMOVAL OF Pb(II) FROM WASTE STREAMS
}

\section{Sivarama Krishna, ${ }^{1,2^{*}}$ K. Soontarapa, ${ }^{1 *}$ Vinay Kumar, ${ }^{3}$ Obaidullah Salehie, ${ }^{2}$ W.Y. Wan Zuhairi, ${ }^{2}$ N. Bakthavatchala Reddy ${ }^{4}$}

${ }^{1}$ Department of Chemical Technology, Faculty of Sciences, Chulalongkorn University, Pathumwan, Bangkok, 10330, Thailand.

${ }^{2}$ Geology program, School of Environmental Science and Natural Resources, Faculty of Science and Technology (FST), University Kebangsaan Malaysia, Bangi-43600, Selangor, Malaysia.

${ }^{3}$ Department of Biotechnology, Indian Institute of Technology Roorkee, Roorkee, Uttarakhand, India.

${ }^{4}$ Ural Federal University, Chemical Engineering Institute Yekaterinburg, 620002, Russian Fedaration

*Corresponding authors, E-mail: svurams@gmail.com (L. Sivarama Krishna), Khantong.S@chula.ac.th (K. Soontarapa).

\begin{abstract}
Removal of toxic pollutants from wastewater, such as heavy metals. It has severed the big problem in the world. Several tools have been established to contract with this problem. In this research paper, Indonesian Kaolin-nanozerovalentiron (IK-nZVI) was synthesized as model adsorbent for $\mathrm{Pb}$ (II) removal from wastewater. The efficiency of IK supported nZVI for $\mathrm{Pb}$ (II) removal efficiency was estimated by accompanying batch experiments. The examined parameters included the amount of IK$\mathrm{nZVI}$, the concentration of $\mathrm{Pb}$ (II) removal and the effect of $\mathrm{pH}$. The results revealed that the IK-nZVI was found to be efficient for the removal of $\mathrm{Pb}(\mathrm{II})$ from wastewater.
\end{abstract}

